\title{
Seeing Space Within and Around the "I"
}

\author{
Ajahn Amaro ${ }^{1}$ \\ Accepted: 3 December 2020 / Published online: 4 January 2021 \\ (C) The Author(s), under exclusive licence to Springer Science+Business Media, LLC part of Springer Nature 2021
}

We bring our attention to the felt sense of the present: the body sitting here; sensations of weight, warmth, or coolness; feelings of alertness or dullness; and the mood of gladness, anxiety, inspiration, and numbness. We feel the body and the breath. We notice the mood. We hear the sound of silence. Here it all is, the array of our experience, here and now.

So much of the practice is bringing our attention to this simple, present, immediate quality of sight, sound, smell, taste, and touch; and form, feeling, perceptions, mental formations, and consciousness. Just this. And we reflect that it is this way. It is this. Such, tathatā. There is the quality of suchness. It is simply this way. It is thus. We do not need to add any more words than that. We just reflect: it is like this.

Tiredness is like this.

Inspiration is like this.

Feeling warm is like this.

Feeling cool is like this.

There is the simple recognition of this present experience that is enough to establish mindfulness, clarity, and wisdom. Mindfulness is the quality which integrates all our experience, even the feelings of things being painful or wrong, broken, not working, and not right. In the midst of unease, there is the recognition: "This is the feeling of not-rightness. This is the feeling of something that is not fixable. This is the feeling of something not working." Right here is this simple apprehension. In this receiving of the felt pattern of that experience, right here, in a deeper way it is fixed, it is whole. To "reflect" is to experience the feeling: "Not-perfect feels like this." It is deeper, more real than simply reciting some words. We do use

Excerpted from The Breakthrough by Ajahn Amaro, Amaravati Publications, 2016.

Ajahn Amaro

ajahn.amaro@gmail.com

1 Amaravati Buddhist Monastery, Hemel Hempstead, Hertfordshire, HP1 3BZ, UK the words but only to lead the heart to open and fully allow an experience of non-perfection.

We give something the label "broken," "imperfect," "incomplete," and "failure," yet these are merely subjective judgments. From its own side, a "broken cup" is not "broken"; it is just exactly what it is. Any "brokenness" comes completely from our human perspective. What one animal looks upon as "waste" another feeds on delightedly; a fallen "dead" redwood tree supports much more life than a "living" one.

When that subjective judging is dropped, and words like "imperfection" or "broken" are seen as convenient fictions, the heart can rest, spacious and accommodating. This allowing of experience is where perfection lies. This is the refuge in awareness, the Buddha refuge. This is the way things are; this is the pattern of reality; clearly seeing that pattern of reality is refuge in Dhamma. Therefore, there is an attunement of the heart, a letting go of selfview. Harmonization of the heart with that reality is refuge in Sangha. This is the safe place, the triple refuge, the Triple Gem. This refuge is always accessible to us, regardless of time, place, or situation. The Triple Gem is our real wealth, our real securitywisdom, reality, and unselfishness.

When a ship is moving toward the destination port, the shoreline appears on the horizon. When we are about to be parting company, going our separate ways after some event, the different elements which have made up the body of that encounter will go their separate ways. They will scatter to the winds. So it is natural for the attention to move toward that port, to schedules, plans, planes, things to do, and places to go. It all feels like a reasonable becoming: "I have to catch a plane." "I have to..." This is a prime opportunity to witness that compulsion of the heart to move on to the next thing, to lean forward into the imagined future, toward projected possibilities. Allow yourself to feel that urge of becoming, bhavatanh $\bar{a}$, planning, expecting, dreading, hoping, and anticipating. See if you can feel it in the body. See if you can feel that urge, that hunger of the mind to move on to the next thing, the relish of having a really good excuse to get wrapped up in some plan, something that is going to happen. Feel it. Know it. Sense it in the body and reflect - the sensation of becoming is dukkha. 
Peace comes from letting go of all that movement. When the attention does not adhere to all that is coming and going, what is present is the timeless reality, a timeless, limitless, allencompassing awareness. That quality of simple knowing is bright, vast, and unbounded. This consciousness is formless, infinite, radiant, and clear. As soon as the attention locks onto a thing, a thought, a plan, or a feeling, right there is birth in the realm of comings and goings, getting and losing, approval and disapproval, and success and failure. When the mind begins anticipating and planning, this is a prime opportunity to see, feel, and know that urge to adhere, to get stuck onto things and into things. A clock is moving inexorably on; the days and nights are relentlessly passing. Time moves on without a pause, without a break. There are things to be done, spaces to be tidied, and taxis to be ordered.

Yes, there are indeed things to be done on the material plane. There are things to be done on the sensory plane. But notice what it feels like when the heart is caught in that sensory swirl, the flush and rush of activity and engagement. There is a gratification, a pleasure in it, but look what comes with it. In the midst of it, see if the heart can let go and be the spacious awareness which provides no footing for long and short, coarse and fine, gain and loss, coming and going, and here and there. Be that aware, open, awakened, spacious place where things do not stick. Feel that fundamental restfulness of non-becoming, the heart not caught in that flow of activity, beginnings and endings, and births and deaths. There is a letting go, a non-grasping. And there are moments when there is non-adherence, a non-entanglement. Let yourself be conscious of how that feels. Feel the presence of the heart free from all grasping, not tying itself to the cycles of birth and death, being off the wheel. Feel it. Let it be known. Let that really sink in. How good that feels, like freedom from an addiction, freedom from a debt, free from being locked up. How delightful, naturally peaceful and enjoyable.

During the day, perceptions will move toward making plans, anticipating the future, dreading it, or looking forward excitedly to it. Whatever the emotional tone, whenever your mind forms the thought: "I will...," "I'm going to...," and "I've got to..."; whenever you notice that thought form, freeze it, stop it in its tracks, and give it some space to be clearly and distinctly seen and discerned. Take that phrase and freeze it. Repeat it steadily in the space of the mind.

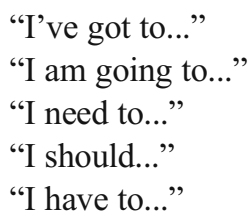

When we take these simple everyday phrases and isolate them and when we let them be clearly known and heard, we begin to see them differently. The heart holds them in a different way. Notice that change. Look at a simple phrase like, "I have to confirm my ticket." When you freeze it, give it some space, listen to it, clarify it, and highlight the "I have to"; there is recognition of an assumption that the universe is incomplete unless some action is taken, the delusion that my life is not whole until some task is completed. The heart knows how ridiculous that is. How could nature be incomplete right now? How could the universe not be absolutely whole right now? What could be missing?

Yet we are so easily swamped by the list of things I have to do, messages I have to answer, and places I have to go - it all seems so real, so important, so compelling. This is a prime opportunity, an ideal opportunity, to see those kinds of compulsions for what they are. When that impulse arises in the mind, notice it. Take the trouble to halt it and clarify it. See the change in the heart when you take a simple phrase like "I should", "I must," or "I've got to" and really listen to it. Let it sit there, hovering in the space of the mind.

Then, to develop this further, as you notice that strange and liberating shift of perspective, refine the statement even further: just say the word "I." Feel the quality of that word-so ordinary, so unremarkable; and yet, when we bring that simplest of words into the clear space of awareness, how strange it is. Something in the heart, our own intuitive wisdom, wonders: "What on earth has that go to do with anything real?" What is "I"? How strange and out of place it can feel. What a weird set of assumptions comes with that word. Let your attention stay with that weirdness, that slightly unsettled feeling. At that moment, the uneasy feeling is coming from the selfview being punctured, destabilized, and dethroned.

Here is another way we can develop this. First, allow the mind to become as calm, still, and clear as possible, with the attention steady in the present moment. Focus on the sound of silence and then drop your name into that open space. "Amaro," "Sita," "Ishmael," "David," or "Ellie," whatever it might be; we bring our ordinary everyday name into the space, the silence of the mind. Just think your own name, with no story, no "should" or "should not", and no characteristics tacked onto it, just your name. And again, notice the strange, unsettling reconfiguration that comes with that. The wisdom of the heart recognizes: "That's not what I am. That is nothing real or substantial." At that moment, self-view is punctured. It is taken out of the driving seat. It loses its strength, its centrality. When self-view is dropped and punctured, along with that subtle disorientation come brightness, peacefulness, and clarity. This is the cessation of becoming, the cessation of grasping; the still heart gives no traction to perceptions, habits of self-view, thoughts, and moods. Completely empty. Transparent.

This is the quality of suchness - tathatā. In a way, all that can be said is: "It's like this." We do not need to have any kind of description beyond that. There is no need to explain or describe or give any kind of conceptual form to it. Even 
calling it an "it" misses the reality. It is the heart of non-grasping, openness, brightness, and clarity.

Let that be known. Let the heart know its own suchness: "It's like this." We do not need to create any more complicated descriptions or explanations beyond that. Just let it be known. The heart is open and clear, for what is happening here is simply Dhamma being aware of its own nature. When the heart is completely free from grasping and free of entanglement, what is being known is Dhamma, the fundamental nature of the heart and of all things; and what is doing the knowing is Dhamma also, nature being aware of what that nature is, Dhamma aware of its own nature. And the flavor of that is suchness.
We can let that sink in and soak fully through our awareness. Let it be completely known, tasted, and realized. Then it is easier not to get caught by the ten thousand becomings, compulsions and urgencies, and opinions and judgments. Their intrinsic transparency, emptiness, and insubstantiality are more obvious. The clearer the realization of non-grasping, of suchness, the easier it is and the greater strength there is to see through the urgencies, activities, busyness, and clamor of the world. The light of our heart is brighter, so it shines through and illuminates the dust of the world.

Publisher's Note Springer Nature remains neutral with regard to jurisdictional claims in published maps and institutional affiliations. 